\title{
SOVIET URBAN POLITICS AND COMPARATIVE URBAN THEORY
}

\author{
JERRY F. HOUGH \\ University of Michigan
}

In appealing for caution in the comparative analysis of urban life in Communist countries, Professor Frolic has correctly pointed to the very considerable difficulties in using the comparative approach in that part of the world. Information often is scarce, and, where it is available, it frequently has not been analyzed by Western scholars in terms that correspond to the theoretical interests of urban specialists. As a result, cross-national comparisons within the Communist world-as well as those between the Communist and non-Communist world-must be made on a very unreliable base, and the opportunity for error is quite great. There is even the distinct possibility that we may be led to include in the same

AUTHOR'S NOTE: The author would like to thank Professors Thomas Anton, Richard Hofferbert, and Charles Tilly of the University of Michigan for very helpful comments on an earlier draft of this paper. and the Center for Russian and East European Studies of the University of Michigan (and Alfred Meyer personally) for an allocation of computer time that made some of the analysis possible. Of course, neither these men nor the Center is responsible for the interpretations made. 
category for comparison phenomena quite different in character.

The introduction of quantitative techniques into the social sciences has sensitized us to the great dangers of generalizing on the basis of a small sample of cases. Obviously, the reliability of broad comparative generalizations will be better as the number of Communist and non-Communist countries that can be included in the comparison in a sound, knowledgeable manner grows large. If I read Professor Frolic correctly, he is really arguing forcefully against the widespread tendency to forget that the increase in coverage is not of much help if the knowledge behind the comparison is not sound. He is really arguing against the widespread tendency to leap to sweeping, abstract generalizations and to draw up comprehensive, abstract taxonomies on the basis of very limited and uncertain knowledge and against the tendency of the discipline to reward this activity very highly. On this, I believe that he is completely correct. Indeed, for this reason, the remarks in this paper will be limited (as the title implies) to the experience of the Soviet Union, the one Communist country the author knows fairly well.

Yet a recognition of the dangers in the comparative approach does not necessarily imply its rejection. Professor Frolic seems to believe that we cannot compare the Sovict Union and China "because the two systems are fundamentally dissimilar," but, even assuming that the systems are that distinctive (and one would want to be very carcful in indicating the features of city life and political process that one has in mind), it is precisely the existence of distinctions that makes comparison interesting. Differences in system and in process stimulate efforts to explain (indeed, if there is no explicit or implicit comparison, there is nothing to explain). while distinctions in policy also provide the opportunity to examine policy impacts.

It is quite true, as Professor Frolic suggests, that the questions we ask in any comparison will normally come out 
of our own culture-and, in fact, they surely should. There seems little reason for a society to pay a man to study such questions as Soviet and Chinese cities (and to teach about them) unless there is something in the experience of other countries which is somehow relevant to the interests of persons in the scholar's own society. Yet, to assert that questions arise out of one's own culture does not necessarily imply that we are always predestined to misunderstand other cultures. Indeed, if such an argument were to be taken seriously, it would destroy the rationale of noncomparative research even more completely than that of comparative research. At least in comparison, one gains some sense of whether the explanation for a phenomenon needs to be sought in the peculiar history or culture of that country or is likely to be found in factors that transcend national boundaries. $^{1}$

Certainly there is little in the experience of Communist studies to suggest that noncomparative work is any panacea. Whatever the virtues or defects of comparative Communism, far more scholars have advocated it than actually used it in a serious way. The same is true of comparative work that focuses on the major theoretical concerns of students of Western urban government. Most Western scholarship on the Communist world has been undertaken by persons trained in area studies-persons who usually have been most interested in the theoretical questions of prime concern to other area specialists. (The direction of the evolution of the system has probably been the foremost among these questions.)

The results of this strictly area approach have not been encouraging. One unfortunate consequence has been that specialists on the Communist world have often derived their definitions of concepts and their interpretations of phenomena either from scholars working in the Communist countries themselves or from the totalitarian model (or the "directed society" models that have succeeded it; for a brief survey of these models and a number of references to articles advancing 
them, see Hough, 1972: 25-26), and they have thereby sacrificed comparability with the studies of scholars working on the West. They also have frequently not realized the importance of what they see in terms of the theoretical interests of Western social science as a whole. A second unfortunate consequence has been that the very considerable knowledge accumulated by specialists on the Communist world (and often even the names of books and articles written by them) does not come to the attention of students of urbanization and urban politics in other parts of the world and that a whole body of experience has not been properly incorporated into Western theory on the subject.

For these reasons, it would be a shame if recognition of the dangers of the comparative approach were to prevent us from avoiding the dangers that the noncomparative approach entails. What is needed, I think, is an acute awareness of the fact that even the description of phenomena in a single country (particularly phenomena such as degree of centralization or autonomy) is inevitably a comparative one. What is needed is a determination on the part of Communist area specialists to acquire the type of comparative base that will permit us to make sophisticated judgments about what is and is not distinctive about Communist cities and their political systems.

\section{GATHERING DATA}

The major conceptual danger in cross-national studies is not that we will use concepts from our culture in framing our questions and in guiding the collection of information. The danger is that we will use concepts that are too ill-defined to permit the collection of truly comparable data or that are so ambiguous that we unknowingly shift our definition of them as we collect data in different settings. Specifically, when we study the Communist world and compare it with the 
non-Communist world, there is the danger (a danger which our best comparative scholars repeatedly fail to avoid) that we will unconsciously shift our definitions so that the information collected in the Communist and non-Communist world will correspond to the assumptions of the totalitarian and democratic models respectively.

There is, I think, such a danger in one of the central concepts which Professor Frolic uses in his comparative analysis-that of urban autonomy-and it may be that many of his doubts about comparison flow from his experience with this concept. Professor Frolic speaks of the relative lack of autonomy of the Soviet (and Chinese) city and the very centralized nature of the system in comparison with North American cities; unquestionably he is right about the lack of urban autonomy in the Soviet Union. He could, in fact, have gone beyond a discussion of central intervention in city decision-making to discuss provincial (oblast) intervention as well. The provincial boundaries are drawn in such a way in the Soviet Union that the province centers upon the largest city in the area, and hence (unlike the situation in the United States) the major industrial, educational, and cultural centers of the country are also usually provincial capitals as well. (Thus, 66 of the 75 largest cities in the Soviet Union-those with a population of over 265,000 persons in 1970-were either republican or oblast centers. $)^{2}$ The responsibility of the regional party officials for regionwide plans in all spheres of life (including those such as industry and construction) means that they are surely going to be very interested in decisions affecting the largest city in the region, particularly since it is the city in which they themselves live and work, and that they are, in fact, going to participate in many of these decisions. ${ }^{3}$ Just as obviously, the impact of that participation will be very difficult to disentangle from the impact of city officials, especially since the party first secretary of the capital city is almost always a member of the bureau of the regional party committee. (This is one reason 
that there have been so few books by specialists on the Soviet Union which focus on the city as such.) $)^{4}$

But what does the concept of autonomy mean and what evidence do we have for a comparative judgment? Certainly a city in any integrated society is not autonomous from higher political bodies on many issues, and any meaningful comparison demands that we talk about the same type of issue in all parts of our comparison. The questions discussed in Dahl's study of New Haven, for example, are the location of a new school, the decision to seek federal funds to carry through a local redevelopment project, and the nature of some of the details of that project. Are we really sure that on this type of question Soviet city decision makers are less autonomous than those in New Haven? Scarcely, for we have never studied this kind of issue in the Soviet Union.

Consider, for example, the fact that the 1962-1970 increase in the per capita housing in the regional capitals in the Russian Republic ranged from $4 \%$ at one extreme to $53 \%$ at the other. The 1962 population of the city, its level of per capita housing in 1962, and the nature of region (whether or not it is an autonomous republic populated in large part by non-Russians) explain $32 \%$ of the variance, ${ }^{5}$ but, as Table 1 indicates, much remains unexplained. Articles in the Soviet press sometimes suggest that new industrial development (a variable on which information is not readily available) is enormously important in the acquisition of new housing, but, it turns out, neither the absolute nor the percentage growth in population adds anything to the explained variance. Is it not at least possible that the differences in the rates of increase, not unlike differences between federal funds spent in New Haven and other American cities, are sometimes (perhaps often) related to the energy and skill of local officials in obtaining funds from the outside?

Similarly, on the type of questions that are usually cited as evidence of a lack of autonomy of Soviet cities, the American city officials too usually have no great control of events. 
TABLE 1

INCREASE IN PER CAPITA LIVING SPACE

IN 71 REGIONAL CAPITALS IN THE RSFSR, 1962-1970

\begin{tabular}{lcc}
\hline \% Per Capita Increase & 1962 Population & 1962 Population \\
in Living Space & Under 200,000 & Over 200,000 \\
\hline
\end{tabular}

Under 8.25 Square Meters of

Per Capita General

Living Space in 1962

Increase under 20\%

Increase over $\mathbf{2 0 \%}$

12

3

$9 \quad 15$

8.25 or More Square Meters

of Per Capita General

Increase under $\mathbf{2 0 \%}$

10

Increase over $20 \%$

0

11

SOURCES: Narodnoe khoziaistvo SSSR: Statisticheskil sbornik, 1961-1969 and Narodnoe khoziaistvo RSFSR: Statisticheskii sbornik, 1961-1969.

Whatever the influence of the economic elite upon city politics in the United States, there is very little evidence that the city has much influence over the decisions of the city economic elite. The dependence of the city upon the property tax means that city officials almost inevitably must be sympathetic to development which will increase the tax base (assuming that we are not talking about very upper-class and wealthy communities for whom revenue is not a major problem), and the ability of owners to move industries out of town may give city officials relatively little real power to increase the mill rate or the assessed value of a plant beyond a certain point. On a great many other questions as well, the character of the city local officials "govern" is determined by decisions made by a national corporation, by the state government (especially on the possibility of amalgamation with the suburbs), or by the federal government (for example, the highway construction and FHA loan programs). Indeed, even on rather detailed questions, urban officials frequently must work within rather stringent state or federal directives or guidelines. ${ }^{6}$ A person who is dubious about the possibility of identifying nondecisions in the American city 
might find it quite useful to look at the restrictions on Soviet urban officials and attempt to think of functional equivalents.

Given the fact that Banfield and Wilson encounter great difficulty in defining urban autonomy in the United States and that Anne-Marie Walsh reports the same result in her summary of the thirteen cities examined in the International Urban Studies Project, given the combination of the restrictions on city officials in the Soviet Union and their membership in the key provincial party bureau, it seems absolutely clear that it is not possible to speak of city autonomy anywhere and that, at best, it is extremely difficult to make meaningful and comprehensive analyses of the degree to which it exists. I suspect that, at the present stage of the development of our discipline, variables such as the general level of centralization or of urban autonomy must be used with the greatest of care and perhaps should not even be used at all.

\section{USE OF COMPARATIVE APPROACH}

How then should the comparative approach be employed when we study the Communist world? To a large extent, of course, the answer to these questions depends upon the interests of the scholar, for there are as many interesting comparisons as there are interesting questions. However, it seems to me that Professor Frolic is generally right when he criticizes a comparative approach which focuses on Communist countries alone. The amount of Western scholarship on many Communist countries is very small (China is far from the least-studied nation in this group), and a scholar who himself attempts to utilize primary sources to engage in comparative work faces formidable language problems. Perhaps more important, to limit the comparison to Communist countries alone courts the danger which Alfred Meyer has 
emphasized-that we will continue to employ "concepts and models reserved for it alone or for it and a few other systems considered inimical" (Meyer, 1967: 11), and thereby hinder comparative analysis in general. Although there surely are a great number of valuable comparisons that could center on the Communist world alone, it is likely that comparisons involving both Communist and non-Communist countries will prove most useful.

Within the framework of an East-West comparison, innumerable types of questions are possible. A scholar interested in purely institutional questions, for example, will find many specific organizational arrangements worthy of study and comparison. Even if the attempt to measure the general level of autonomy or centralization may be inordinately difficult, the Communist experience with small administrative units within the city (e.g., the microraion and commune mentioned by Professor Frolic, as well as that of the urban borough as a whole) surely might provide the basis for a fruitful comparison. The experience of the many forms of public participation (e.g., the public committee in each apartment house; see, e.g., Rudden, 1966) might prove equally interesting.

From a broader theoretical perspective, however, the most useful institutional questions may well revolve around the enormously broad responsibilities assigned the urban political authorities in the Communist countries. Unfortunately, this phenomenon has been obscured in much of the Western work on Communist cities, for, at a time when political science has begun to define government or political system in broader terms, ${ }^{7}$ scholars working on the Communist urban scene have often been extremely traditional in focusing on the formalistic structure of government (in the Soviet Union, the city soviets) in their work. Like Professor Frolic, they usually recognize that "the city party organization makes the key decisions within the municipality," but then, in analyzing the Communist city, they mention only the soviets in their 
discussion of structure and process (particularly true, e.g., of Cattell, 1968). They make statements (e.g., "Soviet and Chinese city governments have practically no effective control over industries located on their territories') which are accurate insofar as the soviets are concerned, but are quite inaccurate when city government is defined in any realistic sense.

From the point of view of any meaningful cross-national comparison, of urban political systems or political processes, the Moscow "city council" is not the executive committee of the soviet (the gorispolkom), but the bureau of the Moscow city party committee (the gorkom). Even in strictly, indeed almost traditional, institutional terms, the mayor of Moscow is not V. F. Promyslov, the chairman of the executive committee of the soviet, but V. V. Grishin, the first secretary of the Moscow Party committee. The party organs and officials do not simply have informal "influence" in the Soviet city; they have, as I have tried to suggest by applying the label "prefect" to them, very clear-cut formal and legal authority "to lead the soviet, economic, and public organizations... to unite, to direct, and to verify [their] activity... [to bear] complete responsibility for all sides of political, economic, and cultural life" (Hough, 1969: 101-108).

In practice, the leadership provided by the city party committee is of the most concrete type. It is not limited to major planning decisions, but also involves very detailed coordination of urban construction. In this work, the party organs not only "continually coordinate, 'settle' questions, and call economic leaders to conferences" (Partiinaia zhizn, 1965), but they also regularly establish formal institutions (called "staffs"), headed by a party official and composed of relevant city and industrial officials, to supervise work on individual projects. In the words of the first secretary of the Cheliabinsk city committee (Hough, 1969: 193): 
Until recently... it was fashionable for us (and obviously not only for us) to create all possible staffs-one for the construction of heating lines, one for the blast furnace, one for the rolling mill, one for the water line, etc. A responsible Party official-as a rule, a secretary of the Party committee, raikom, or gorkom-was appointed the head of each staff. And this head often led operational conferences, interfered in the decision of purely technical problems, shouldered the responsibility for many minor questions of materials supply, etc. The author of these lines had to appear more than once in the role of such a "staffist" [shtabist/.

The first words of this quotation suggest that such staffs had been discontinued in the wake of Khrushchev's removal, but subsequent articles made quite clear that they are a regular feature of the Soviet urban scene. The construction of a water line, the program for the construction of housing services, a project to lower the water level of the Volga during flood-time, the construction of major industrial plants and (in all but the very largest cities) of new housing and schools all of these have been supervised by party-headed stafis.

The same administrative fact of life that requires the creation of party staffs - the lack of authority of the sovicts over most industry and construction-also requires party. involvement in almost any question concerning the relationship of industry and construction to other institutions and organizations in the city. ${ }^{8}$ The independence of railroad transportation, higher educational institutions, and the procuracy from the sovicts has the same consecpuence in their casc, and, in addition. the party organs can and often do provide policy guidance and make key personnel decisions in areas supervised directly by the soviets. At times, extremely detailed questions of such a nature are decided at sessions of the party bureau or at other party mectings: "How to prepare a stand and what side of the street on which to locate it. Where to hang a street sign. How to conduct the strect cleaning" (Pravda, 1965). 
Party officials also have the ability to intervene in the internal operations of such institutions as the industrial factories. They can (and not infrequently do) force the plant manager to replace one of his subordinates, to give higher priority to the delivery (or production) of a particular order for a particular customer, to introduce a given technical innovation, to send workers to aid temporarily in the harvest, in the work of city government, or on an urgent construction project (Hough, 1969: chs. 7-11). They have analogous authority over the leading officials of stores, colleges, hospitals, theaters, schools, and other institutions.

Therefore, in comparative institutional terms what is striking about the Soviet city is not that the city political authorities lack autonomy (that phenomenon is to a very considerable degree universal), but that they have enormous authority to intervene in all types of decisions made within the city (including economic decisions that are entirely within the private sector in the West) and that they frequently exercise this authority. The consequences or nonconsequences of this "broadening of the political system" in the Communist city is of major theoretical interest.

\section{OTHER COMPARATIVE WORK}

If a scholar is interested not so much in institutional comparisons as in processes and in informal structure of power, he will find that any direct comparative work involving the Soviet Union will often be frustrated by difficulties in data collection. A community power study employing the methodology either by Robert Dahl or by Floyd Hunter cannot be carried out in the Soviet Union because of the impossibility of obtaining the particular type of interviews required, while an examination of the role of collective violence in the urban political process is enormously complicated by the strict censorship exercised over the reporting of such incidents in the press. 
Nevertheless, even if exact replication of these types of "process" studies are not possible in the Soviet Union, there is enough information available about the Soviet urban experience to provide insight into the questions these studies explore. For example, Charles Tilly (1969, forthcoming a, forthcoming b), among others, has been insisting that collective violence has been a "regular," a "normal" part of the basic Western political process-not simply an anomaly associated with the early strains of industrialization. In a peculiar way, the Soviet city tends to support that position. Despite the absence of competitive elections and the right to conduct peaceful demonstrations and to strike (mechanisms that are often interpreted as useful in relieving social tension), the Soviet city has seen nowhere near the scale of collective violence incidents that have been found in any period of French history (to take the country studied most intensively by Tilly). The explanation seems to be not simply that the Soviet authorities are ruthless in quelling riots (much of the violence in the West, particularly against persons, comes from the police and the armed forces of the state), but also that they have been effective in repressing many of the types of "peaceful" collective behavior that are legitimate in the West. From this perspective, as Tilly's model would seem to imply, it is not strange that there should be a relative absence of large-scale collective violence incidents in a country in which there is the absence of competitive elections and the right to conduct peaceful demonstrations and to strike; indeed, it might have been more appropriate to use the phrase "partly because of the absence of" earlier in this paragraph, instead of "despite of."

What, however, is the significance of the difference in this aspect of urban political life in the Soviet Union and the West? Unfortunately, students of collective violence in the West are still in the stage of exploring its patterns and causes and have done little work on its consequences, but a comparison on this latter point might prove very interesting. 
Large-scale collective violence incidents occasionally do occur in the Soviet Union, and over the last dozen years, for example, cities such as Temir-Tau, Novocherkassk, Chirchik, and recently Kaunas have had major demonstrations and strikes. ${ }^{9}$ Despite the relative infrequency of such incidents, I have tried to suggest that the threat of collective violence is a major factor in ensuring some sensitivity of local party leaders to the wishes of the local population, for such incidents seem to have disastrous results on the career not only of a city, but also of regional officials (Hough, 1971: $66-68,79) .{ }^{10}$ Hopefully someone will utilize dissident and refugee sources (the number of recent Jewish refugees is very large now) to try to gather more systematic data on large-scale collective violence incidents in the Soviet Union. Verification of information would be a great problem, but it is possible that such incidents are more numerous than suspected and that their consequences on outcomes can sometimes be traced.

Similarly, despite the impossibility of conducting a classic community power study in the Soviet Union, we still are in a position to learn much about the structure of power in the Soviet city. As Sayre and Polsby (n.d.: 135) acknowledge, "Most descriptions of American urban decision-making patterns [do no more than] at tempt to demonstrate either that a ruling elite exists or that it does not," and information about the Soviet city is not so scarce that the basic Dahl-Polsby test for a ruling elite cannot be used in a general way. The results of doing this are very instructive. While many American scholars tend to treat the Soviet Union as if it were governed by a ruling elite, the Dahl-Polsby test indicates exactly the opposite to be true in the Soviet city. ${ }^{1}$ The city party officials have great authority (and the soviet officials too have a role in decision-making), but if the major question of American community studies is raised-whether an economic elite rule-then it is quite apparent that industrial interests are victorious a very large percentage of 
the time. The party first secretary of the city is often an engineer with managerial experience in local industry, ${ }^{12}$ and, in practice, he often is timid in overruling the wishes of the city's "rich uncles" in the interests of comprehensive city planning, pollution control, or the living conditions of the city population as a whole. ${ }^{13}$ In his dissertation (soon to be published in revised form) William Taubman (1969) documents this phenomenon at great length and concludes that the Soviet city to all extents and purposes is frequently a "company town" (see also Osborn, 1970: 222-228; for a contrary view, see Frolic, 1970: 692). In the perspective of the American comparison, this label is a very appropriate one (I only wish that I had thought of it myself), but, as has been seen, it does remain an easily documented fact that the party officials sometimes do make decisions which the industrial managers do not like-even decisions which affect the running of the factories themselves. Moreover, in a series of nonindustrial realms, local officials are in "dual subordination" to a ministerial line of command as well as to local political authorities, and this fact, plus their own specialized knowledge, ensures that they are not without influence on decisions in their own sphere of activity.

Hence it is clear that if the Dahl-Polsby test for a ruling elite is applied to the Soviet city, then the finding is precisely the same as when it is applied in the United States-"the existence virtually everywhere of 'pluralistic' systems of decision-making" (Sayre and Polsby, n.d.: 127). Whether the ruling elite is thought to be the party secretaries or the industrial managers, it is not true that in "all or very nearly all" of the cases "the alternative preferred by the ruling elite is actually adopted" (Dahl, 1958: 464). There is no "small group ... which [is] united in its policy aims and consistently [gets] its way in more than one significant policy area" (see Hough, 1971, for a discussion of the various cleavages within the party apparatus at all levels). Open political conflict takes place within the elite rather than between the 
upper and lower classes. And, finally, despite the company town label, it still does not seem quite right to say that "political and civic leaders are subordinate to the upper class... [and] take orders from or do the bidding of the upper class" (Polsby, 1963: 8-1 1, 90, 93).

The fact that the Soviet urban political system is pluralistic by the Dahl-Polsby test could, of course, be interpreted in several ways. One could speak simply of a universal urban culture in industrialized society. Or one could raise the question of whether the Dahl methodology really illuminates much about differences in actual political systems. Certainly if anyone thinks that all decisions in any modern city are made by a very small group of any type, the Dahl-Polsby test does remind us of certain immutable facts about the political process in any modern society, but if one is interested in comparing urban political systems, then it seems to be that the test serves little purpose. ${ }^{14}$

Once it is recognized that every political system must be pluralistic by the test we are using, then the need to be very careful in our discussions of pluralism becomes very obvious. Concepts such as centralization, pluralism, autonomy, and public participation have very positive connotations, and they often are treated as if they dealt with the same phenomenon. (The following phraseology is not atypical: "Decision-making is hierarchical in Soviet cities, but it is shared in North American cities"; Frolic, 1970: 691). Yet, one might argue that one factor ensuring the "pluralistic" nature of Soviet urban decision-making (in terms of the Dahl-Polsby test) is precisely the high degree of centralization in the system as a whole. It is the subordination of specialized urban officials to powerful central ministries, it is the financing of most urban projects through these ministries that inevitably requires the local political leadership (or other local elite) to defer to specialized urban officials on many questions, particularly those of a specialized nature. Greater autonomy for the city might well mean greater 
ability for a local elite to concentrate power in its hands and less pluralism in the sense of minority rule within city politics.

Similarly a very high degree of centralization on a great many questions is not inconsistent with a high degree of effective public participation on others. It is at least possible that the conventional view about citizen participation in the Soviet Union ("Although large numbers of citizens are elected to the several local soviets and various public committees in the city, they have little or no part in or influence on local politics or administration"; Cattell, 1968: 26) does not really apply on the type of question that Dahl studied in New Haven. On the question of pluralism, as well as that of autonomy, we must be very careful in specifying the type of decision which we have in mind.

\section{NEW SUGGESTIONS FOR COMPARATIVE ANALYSIS}

The type of comparative analysis that is, I think, likely to be most fruitful in the utilization of the experience of the Soviet city is that which focuses on outcomes within urban areas-not simply outcomes in terms of budgetary outlays, but outcomes in terms of "who gets what," outcomes in terms of the pattern of the distribution of values in the city. It is on this type of question that most data are available and that interviews often prove most revealing. Moreover, while Professor Frolic suggests that "Soviet cities have more in common with North American cities than with their Chinese counterparts," there are many striking differences between Soviet and American cities which can form the base for very illuminating analysis and explanation.

Certainly, for example, the Soviet urban scene has a political system with a number of obvious differences from its American counterpart-the lack of competitive elections; the impermissibility of almost all demand dramatization 
(e.g., picketing, mass meetings, and street marches) even in promoting demands that may quite legitimately be presented in other ways; a frequency of collective violence incidents that is much lower; the legal authority of urban political leaders to intervene in the internal workings of all institutions and enterprises within the city (and, to repeat, this means all institutions and enterprises in the entire metropolitan area); a pattern of political participation that is quite extensive-not only specialist participation in ad hoc legislative and investigatory committees, but mass participation in voluntary "semi-police" units, library committees, apartment house committees, factory committees of various types, and so forth; the existence of national control over investment and the consequent ability of the political leadership (an ability which, despite the suggestion of Professor Frolic to the contrary, is now being reflected in actual policy $)^{15}$ to follow a deliberate policy with respect to the pattern of urban population growth. (In general, these features of the Soviet urban political system exist throughout the Communist world-a point that might well be considered before one concludes that "cities in both China and the Soviet Union have very little in common.")

The differences between the Soviet and American city go beyond the nature of their political system to include a number of the features of the cities themselves.

(1) The placing of the entire urban area of a "city" within the city limits of the core city and, therefore, under the jurisdiction of the central city political authorities.

(2) The absence of urban sprawl, even within the city limits. Suburban development in the American sense has been virtually absent, and there has not even been much need to annex thinly populated areas around the city (Lewis and Rowland, 1969: 781).

(3) A package of services with a mixture of elements quite different from that found in the United States. Housing, water supply, and consumer services seem well below the American standard 
(even controlling for stage of economic development), while the systems of public transportation, parks, day-care centers, and medical-service centers generally are superior even if one compares the two countries today at their very different levels of industrial development.

(4) The financing and control of much of the housing and urban services (sometimes even including such services as water supply) by organizations other than the local soviets-notably by the major industrial plants in the city. As a consequence, there is a tendency for industrial personnel to live in special "factory" settlements within the city (see e.g., Zadykhina, 1969), and a major tendency for persons in these settlements to receive better quality housing and services than other inhabitants of the city (see Taubman, 1969).

(5) Housing patterns that, so far as can be judged, are much more integrated in terms of social class than those in American urban areas. This may not lead to a great deal more social interaction along class lines, ${ }^{16}$ but it should have a significant impact upon the degree of social-class integration within the neighborhood school.

(6) A pattern of urban development in the country as a whole in which the industrial, political, and cultural-scientific-educational elites of each province are concentrated within the provincial capital rather than being dispersed among two, three, or even more cities, as is typical in the United States.

(7) A nationwide distribution of services in which size of city is a major determinant of the level of services received by its inhabitants, those in the larger cities generally receiving preference in almost all respects. ${ }^{17}$

If we begin to look more closely at this type of substantive difference on a cross-national basis, we will, I think, find that comparative urban studies will be greatly enhanced. Not only is the nature of policy impact and the interrelationship among different policies thereby illuminated, but we find ourselves in a much better position to explore the impact of political variables (such as those suggested in the enumeration of differences between the Soviet and American urban political systems) both upon actual outcomes and upon the 
distribution of power. What, for example, is the significance of the fact that a broad Soviet urban elite (say, the upper ten percent of the population) does not have the type of class exclusivity in its neighborhoods (and in its neighborhood schools) that a comparable American urban elite has sought and won? Is it simply a reflection of different values, is it an indicator of the relative power of the broadly defined elite to obtain what it desires from the political process in each country, or does it have another explanation?

There are a number of questions about outcomes that could be asked, and I suspect that they would lead to a much more sophisticated understanding of the structure of urban power than the vast majority of community studies undertaken to date. Only when we come to a firm understanding of cross-national differences and similarities in urban life are we likely to understand the forces that have produced them, as well as the factors which contribute to the political strength or weakness of these forces in different settings. Indeed, only such a methodology is likely to permit us to make any meaningful comparison of the real distribution of power in urban areas of different countries and any sound generalizations about the relationship of such political variables as competitive elections and political participation to this distribution.

\section{NOTES}

1. Professor Frolic speaks, for example, about the relatively low levels of urbanization accompanying Chinese industrialization, and he attributes this to factors peculiar to China. Assuming that he is right about the level of urbanization (and we certainly should be cautious given the data problems he reports for China), it is interesting to note that two geographers (Lewis and Rowland, 1969: 791) report precisely the same phenomenon in the early stages of Russian industrialization: "Modem Russian industrialization experienced its first rapid increase during the last quarter of the 19th century. Nevertheless, by 1897 its effect on urbanization as a whole was negligible." They cite Jaffe (1959: 14-18) 
to suggest that "the lack of a significant urbanization-industrialization relationship in the early stages of economic development is not unique to Russia and the USSR." I have no expertise whatsoever on this question, but surely it cannot be meaningfully discussed except in comparative perspective.

2. The 29 cities with a population of over 600,000 persons were all republican or regional capitals. The 32 cities with a population between 200,000 and 265,000 persons (that is, those just below the 75 largest) included 21 capitals. The census figures were published in Pravda for April 19, 1970, pp. 1-2.

3. For example, the city of Leningrad contains over $70 \%$ of the population of Leningrad province. The provincial party committee has a special secretary who handles industrial and other urban affairs, five departments in the industrial realm ("industrial" which supervised heavy industry, defense industry, light industry, and food industry, construction and building materials, and transportation-ommunication), and since 1953 its first secretaries have always been engineers with managerial experience in industry and some background in government or party work in the city of Leningrad (see Hough, 1972: 17, 54). It is difficult to imagine what these officials are doing if they are not participating in decisions involving the provincial capital.

4. Consequently, those who would like to acquaint themselves with scholarly work of relevance to specialists on urban government should include two books which explicitly focus at the provincial level: Fainsod, 1958; Stewart, 1969. In addition, there are innumerable books and articles on specific policy areas, which in practice become "urban books" because of limited information available about the countryside. A typical example of this phenomenon is Connor, 1972, which contains a thorough discussion of such questions as juvenile delinquency and alcoholism control in the Soviet city.

5. Per capita housing increased most in the Russian cities (only 5 of the non-Russian cities had an increase more than the mean $20 \%$, compared with 11 with an increase less than the mean), and the more populous cities in 1962, as well as those with the lowest per capita housing in that year, had the largest increases (see Table 1).

6. See Banfield and Wilson (1965: ch. 5) for a short, but illuminating discussion of this problem.

7. In the words of Gabriel Almond (1956: 393, 395), for example, "the term system satisfies the need for an inclusive concept which covers all of the patterned actions relevant to the making of political decisions.... The concept of system implies a totality of relevant units... The political system [is] the patterned interaction of roles affecting decisions backed up by the threat of physical compulsion."

8. The party first secretary in a medium-sized Ukrainian city described the situation very accurately: "In our city there are four construction trusts and over thirty sub-contracting organizations. As a rule, they are subordinated to different departments, but they work on one project. Since there is not an economic organization in the city which could coordinate their activity, the Party gorkom has to assume that role" (Partiinaia zhizn, 1965).

9. From a theoretical point of view, it is interesting that all of these are medium-sized cities (Kaunas is the largest at 300,000) rather than the type of 
metropolitan center in which much of the collective violence of Western cities originated.

10. For example, after the strike at Temir-Tau, the five regional Party secretaries were removed in addition to the city officials, and the regional first secretary was demoted to the level of shift head in a plant.

11. The same is the case if the test is applied to the national scene, even during the Stalin period. This will be discussed at some length in Hough (forthcoming).

12. An examination of the biographies of first secretaries in fourteen of the largest cities in the RSFSR and the Ukraine in 1966 reveals thirteen engineers. Despite their relative youth (their average age was 44 ), nine had at least a decade of engineering-managerial experience in industrial, construction, or railroad transportation before being transferred to party work, and four had been enterprise managers. In twelve capitals of the union republics (where supervision of local intellectuals is particularly important because of the problems of nationalism), eight were engineers but only one had substantial managerial experience. Here, as elsewhere, however, a lower secretary almost always had such experience (Hough, 1971: 73). Biographies have been found for sixteen additional men who were city first secretary at some time in the period since 1966. Neither of the two men in non-Russian capitals had managerial experience (although the new first secretary in Minsk had been chairman of the executive committee of the soviet for thirteen years), but the other thirteen (including six in smaller cities in the non-Russian republics) included eleven engineers. Five of the thirteen had a decade of experience in industrial administration (three as plant manager or higher), another had been a factory manager with seven years of industrial experience, another a director of a petroleum-geological research institute, another a deputy head of the republican organization for supplying technology to agriculture, and another a deputy chairman of the city soviet with five years of work in industry.

13. The quotations come from an article about the city of Krivoi Rog. Quoted in Hough (1969: 240-241).

14. The most obvious and unnecessary problem with the test is its insistence on an elite unified on all questions. Dahl and Polsby both define an elite simply as a group "less than a majority in size" and a ruling elite simply as "a minority of individuals whose preferences regularly prevail." By this definition, the entire white minority in South Africa could be seen (and quite rightly so, it seems to me) as a ruling elite vis-à-vis the black majority, but the divisions within the whites presumably mean that they are not a ruling elite according to the Dahl-Polsby test.

The more basic problem with the test is its failure to take account of the fact that no human being or group can ever be omnipotent. Let us imagine, hypothetically, that a community or a nation does have a ruling group, but a ruling group that, of course, cannot have everything it desires. Assuming that the nonelite members of the population eschew a revolutionary strategy, they should assume that the ruling group will surely yjeld on some questions (for reasons of public relations, legitimacy, and high productivity in the work of the nonelite, if nothing else), and they should treat politics as "the art of the possible," making 
demands or perhaps suggestions that seem within the realm of the possible. If they move the political battleline to the point where the ruling elite might well adjust its policies (their proper strategy), if they judged the power situation correctly, they will, in fact, have a fair chance of winning. And, as a consequence, the pluralist test will always demonstrate that no ruling elite exists.

15. As Professor Frolic emphasized, the statistics on urban growth prior to the 1959 census belied the officially proclaimed policy of limiting the growth of the largest cities (see Lewis and Rowland, 1969: 776-791, esp. 781, for a careful documentation of this phenomenon in the period prior to 1959). However, in the period between the 1959 and 1970 censuses, this pattern of rate of growth changed. At least for the size of city for which information is now available, the relationship between city size in 1959 and rate of growth between 1959 and 1970 was curvilinear: $1,000,000+-21 \% ; 500,000-999,999-34 \%$; $300,000-499,999-39 \% ; \quad 200,000-299,999-43 \% ; \quad 150,000-199,999-50 \%$; $125,000-149,999-39 \% ; 100,000-124,999-35 \%$. (Except for the over-1,000,000 group, each of the groups in this analysis had between 21 and 27 cities in it.) Of course, the percentage of the total population in cities over 500,000 in the country grew more rapidly, for 9 entire cities moved into this category for the first time in the census period (for a general discussion of the policy and nature of urban growth, see Listengurt, 1971).

16. Soviet sociologists are discovering that higher-status citizens apparently do not make many friends in their place of residence, but instead socialize with persons they meet at work (Frolic, 1970: 682-684).

17. For example, the provincial capitals of the RSFSR with a population of under 250,000 in 1962 had an average of 8.04 square meters of general living space per person, those with a population of $250,000-500,000$ had 8.30 square meters per person, those with $500,000-1,000,000$ persons had 8.53 square meters, and those with over a million people had 9.26 meters. In 1970 (with a somewhat different list of cities involved) the pattern was very similar: under 250,000-9.46 square meters; $250,000-500,000-10.00$ square meters; $500,000-1,000,000-10.27$ square meters; over $1,000,000-11.06$ square meters.

\section{REFERENCES}

ALMOND, G. A. (1956) "Comparative political systems." J. of Politics 18 (August).

BANFIELD, E. C. and J. Q. WILSON (1965) City Politics. Cambridge, Mass.: Harvard Univ. Press.

CATTELL, D. T. (1968) Leningrad: A Case Study of Soviet Urban Government. New York: Frederick A. Praeger.

CONNOR, W. D. (1972) Deviance in Soviet Society. New York: Columbia Univ. Press.

DAHL, R. A. (1958) "A critique of the ruling elite model." Amer. Pol. Sci. Rev. 52 (June). 
FAINSOD, M. (1958) Smolensk Under Soviet Rule. Cambridge, Mass.: Harvard Univ. Press.

FROLIC, B. M. (1970) "The Soviet study of Soviet cities." J. of Politics 32 (August).

HOUGH, J. F. (forthcoming) Defining Responsive Government: The Implications of the Soviet and American Experience.

-- (1972) "The Soviet system: petrification or pluralism?" Problems of Communism (March/April).

$---(1971)$ "The party apparatchiki," in H. G. Skilling and F. Griffiths (eds.) Interest Groups in Soviet Politics. Princeton: Princeton Univ. Press.

-- (1969) The Soviet Prefects: The Local Party Organs in Industrial DecisionMaking. Cambridge, Mass.: Harvard Univ. Press.

JAFFE, A. J. (1959) People, Jobs, and Economic Development. New York: Free Press.

LEWIS, R. A. and R. H. ROWLAND (1969) "Urbanization in Russia and the USSR: 1897-1966." Annals of Assn. of Amer. Geographers 59 (December).

LISTENGURT, F. M. (1971) "Problems in the formation of the population of cities in the RSFSR." Soviet Geography 12 (February): 117-123.

MEYER, A. G. (1967) "The comparative study of Communist political systems." Slavic Rev. (March).

OSBORN, R. J. (1970) Soviet Social Policies. Homewood, Ill.: Dorsey.

Partiinaia zhizn (1965) November, no. 22: 36.

POLSBY, N. (1963) Community Power and Political Theory. New Haven, Conn.: Yale Univ. Press.

Pravda (1965) February 24: 2.

RUDDEN, B. (1966) "Soviet housing and the new civil code." International and Comparative Law Q. 15 (January): 242-244.

SAYRE, W. and N. POLSBY (n.d.) "American political science and the study of urbanization."

STEWART, P.D. (1969) Political Power in the Soviet Union: A Study of Decision-Making in Stalingrad. Indianapolis: Bobbs-Merrill.

TAUBMAN, W. (1969) "The politics of urbanization in the USSR." Ph.D. dissertation. Columbia University.

TILLY, C. (forthcoming a) "The chaos of the living city," in The Building of an Urban World Boston: Little, Brown.

--- (forthcoming b) "Revolutions and collective violence," in F. I. Greenstein and N. Polsby (eds.) Handbook of Political Science. Reading, Mass.: Addison-Wesley.

- - (1969) "Collective violence in European perspective," pp. 4-42 in H. D. Graham and T. R. Gurr (eds.) Violence in America. New York: NAL.

WALSH, A. H. (1969) The Urban Challenge to Government. New York: Frederick A. Praeger.

ZADYKHINA, K. L. (1969) "Ethnographical data on the mode of life of the Uzbek workers of Tashkent and Andizham," pp. 205-225 in S. Dunn (ed.) Sociology in the USSR. White Plains, N.Y.: International Arts and Science. 